\title{
Antiretroviral treatment algorithm compliance: a regional audit and survey
}

B Howe, C White, B Elawad, DA Price, T Lavender, S Bushby, J Foster, J Hussey.

\section{Background}

In 2015 BHIVA introduced new treatment guidelines [1] and NHS England produced an algorithm for antiretroviral treatment (ART) initiation - with Kivexa ${ }^{\circledR}$ (abacavir/ lamivudine) backbone and efavirenz third agent as first-line and a requirement to have regional and local multidisciplinary team (MDT) arrangements to aid decision making.

\section{Methods}

6 services within our regional clinical HIV network each carried out a retrospective audit of 20 (or total if fewer) cases started on ART in 2015, and completed a survey of each centres MDT arrangements.

Data from each centre was collated and analysed.

Figure 1. ART regimen initiated pre- and post introduction of treatment algorithm

Jan-Mar (n=18) pre-algorithm

Apr-Dec $(n=80)$ post algorithm

\section{Figure 2. Reasons for choosing non-first line regimen}

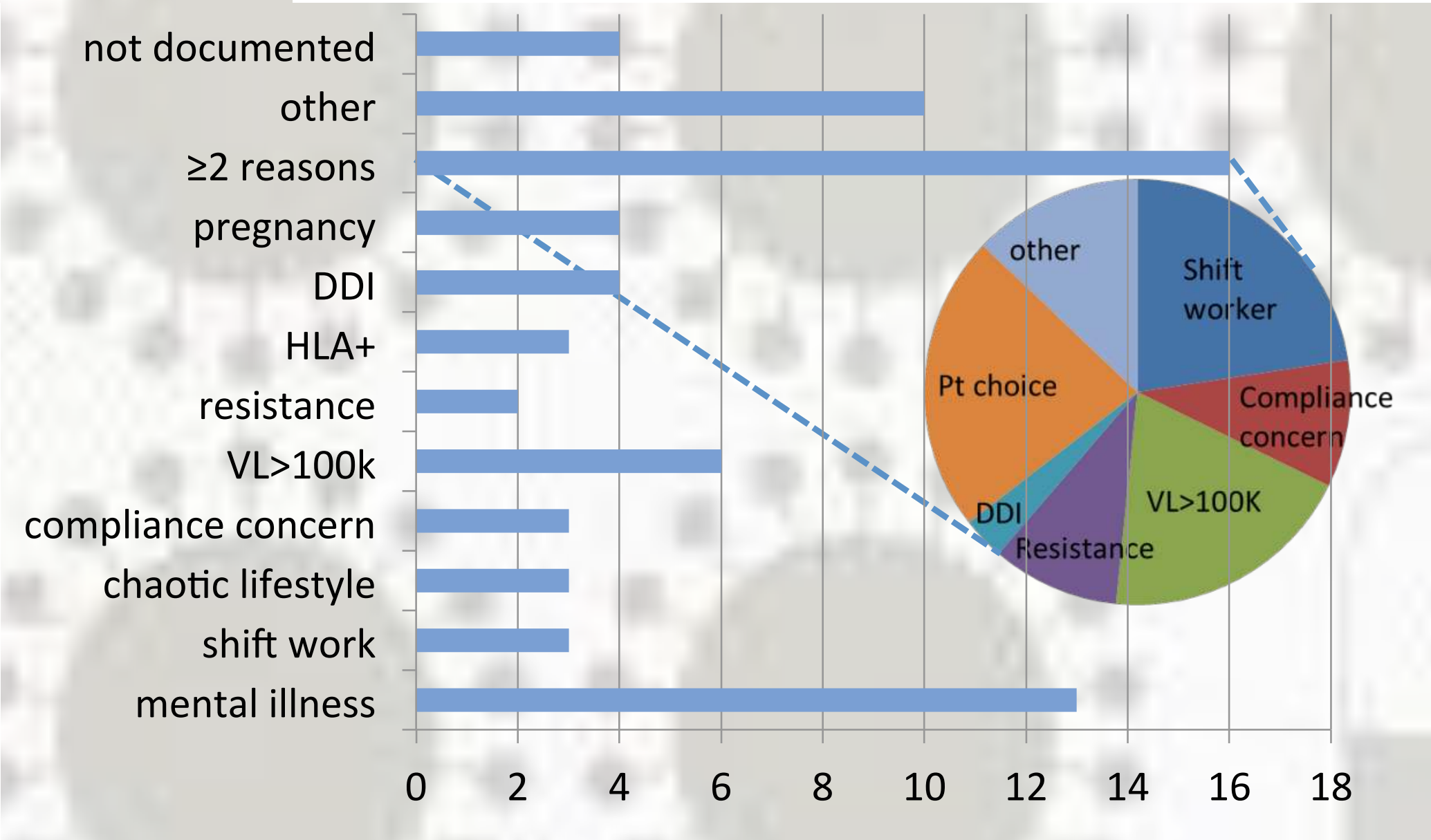

\section{Results}

- Local MDTs varied in composition and number of professionals

- All centres reported a change in practice

- All discussed non-first line regimens

- 98 case notes were audited.

- Reasons for starting included, 43 for CD4 <350, 17 for primary HIV infection or symptoms, 16 for Treatment as Prevention, 14 patient choice.

- $88(90 \%)$ were compliant with the algorithm. 7 non-compliant, 3 insufficient documentation.

- An increase in abacavir/lamivudine based regimens was seen after algorithm instigation in April 2015 (Figure 1) - from 38\% Kivexa ${ }^{\circledR}$ based ART pre-algorithm to $73 \%$ after introduction.

- Commonest reasons for non-first line choice were: mental illness, HIV viral load $>100 \mathrm{~K}$, patient choice and shift work (Figure 2).

- $90 \%$ overall compliant with the NHS England treatment algorithm.

\section{Discussion}

MDT arrangements and interpretation of the algorithm varied in our network. Prescribing practices have changed throughout the region since algorithm introduction. Further work is needed as a network to ensure standardised ARV prescribing for both cost and equity of patient care. 